\title{
La pedagogía de la modernidad. Una aproximación a las formas y contenidos de la enseñanza en Comenio, los Jesuitas, los hermanos La Salle y la Reforma protestante
}

TOMÁS ELIAS ZEITLER

Facultad de Humanidades, Universidad Nacional del Nordeste, Argentina

"La historia de la pedagogía escolar... es la historia de cómo se va organizando el espacio, las relaciones, los roles, el material... para hacer eficaz la enseñanza colectiva."

J. Trilla. "Ensayos sobre la Escueld" (1995: 21)

\section{Introducción}

El presente trabajo es un análisis crítico que busca brindar un panorama general sobre las problemáticas más importantes de la Historia de la Educación durante la Edad Moderna.

Proponemos un análisis de contenido de las propuestas pedagógicas desarrolladas por Comenio, los jesuitas, los hermanos La Salle y las contribuciones de la reforma protestante para dar cuenta de las formas de organización del espacio y las relaciones que instituyeron.

Desde una perspectiva genealógica se realiza un estudio de las propuestas didáctico-pedagógicas actuales para rastrear cuáles de sus elementos constitutivos se encuentran enraizados en la pedagogía de la modernidad.

\section{2. "Didáctica Magna", "Ratio Studiorum" y libros actuales de didáctica: un análisis comparativo.}

Desde un análisis general, que momentáneamente deje a un lado ciertas consideraciones especiales y específicas, podemos distinguir ciertos temas y asuntos que preocuparon a Comenio en su obra y de los padres Jesuitas, y que aun permanecen dentro del campo de las problemáticas didácticas de los investigadores educativos contemporáneos. Contenidos, objetivos, métodos, función social y cultural de la escuela, organización de las disciplinas, organización del aula y de los recursos didácticos: unos y otros siguen siendo temas que están presentes en casi todas las obras sobre didáctica, en algunos casos aparecen reformulados bajo nuevos conceptos y denominaciones para ocultar su trasfondo histórico anclado en la pedagogía moderna ${ }^{1}$; en otros casos se levantan fuertes críticas, a aquel viejo ideal pansófico

\footnotetext{
'Narodowsky (1994:42) afirma que "Tal es la importancia de la propuesta (refiriéndose a la Didáctica Magna) que dentro de la tradición historiográfico-educativa clásica, como de la obra de autores e investigadores más recientes, audaces e innovadores en sus hipótesis, se observa la significativa ponderación de la obra comeniana a favor de hallar en ella... no solamente los gérmenes del actual discurso sobre la escolaridad sino también sus más relevantes y benéficos métodos y preceptos, elementos que garantizarán la perdurabilidad por siglos de la obra.".
} 
que pretendía abarcarlo todo y a aquella racionalidad moderna que buscaba encontrar una explicación causal a toda problemática, que no van mas allá de lo teórico y no proponen nada concreto posible de aplicar en una situación escolar determinada; otros en cambio procuran superar la instancia teórica y avanzar hacia propuestas orientadas a la reflexión, la crítica y las adaptaciones pertinentes.

A Comenio le preocupaba la universalización del mensaje divino, la lectura de la Biblia y la moralización de las masas ${ }^{2}$. Estos principios aun permanecen vigentes dentro del discurso de los Jesuitas ${ }^{3} y$ de los hermanos La Salle, sin embargo, ya no pertenecen al currículo de las escuelas públicas estatales, a excepción de los intentos por imponer una determinada forma de moral secular, y por eso no son consideradas por los investigadores actuales. Por otra parte, el sistema de metáforas de Comenio entre la enseñanza y el orden de la naturaleza, dado su ideal de panteísmo, ya no tiene vigencia, lo que no quiere decir que el deseo por encontrar o fundar un orden educativo no siga existiendo. Sin embargo, el deseo de Comenio por buscar una obediencia reflexiva y pensada ${ }^{4}$ y por centralizar el proceso educativo en la figura central del maestro ${ }^{5}$; el anhelado deseo de los Jesuitas por establecer un sistema educativo meritocrático ${ }^{6}$ e individualizado que organice el espacio ${ }^{7}$ y delimite los roles; y el sueño de los hermanos La Salle por desarrollar una pedagogía que atienda a todos los detalles de la situación escolar, permanecen vigentes a lo largo del siglo XIX y durante gran parte del siglo XX. Sin embargo, estas similitudes de temas no debe conducirnos a establecer otros tipos de paralelismos ${ }^{8}$, dado que tanto las ideas acerca de lo que es la enseñanza como la práctica educativa en sí se han transformado en las últimas tres décadas del siglo XX gracias a las aportaciones teóricas y metodológicas desde distintos campos de la investigación social.

Además, debemos ser conscientes de que los "textos" en sí no son totalidades autónomas que encierran dentro de su discurso el "contexto" en el cual fueron producidas, sino que es necesario enmarcarlos y analizarlos en un "contexto exterior" que influye sobre la producción, circulación y consumo de los mismos ${ }^{9}$. En este caso, el contexto de la Reforma protestante, que llevó a la división de Europa occidental en dos confesiones • como lo analizan Dussel y Caruso (2000)• es central para entender las propuestas didácticas de protestantes y católicos. Los protestantes, y Comenio es uno de ellos, necesitaban de la educación y por lo tanto de la "escuela" y de la "infancia" para instruir a los fieles en la nueva fe y asegurar asi el triunfo de los principios religiosos que ellos defendían, para lo cual Comenio diseñó una propuesta didáctica que respondía a las necesidades de este grupo social: la burguesía que se oponía al dominio del

\footnotetext{
2 "No deben tratarse otros asuntos sino aquellos que tienen aplicación segurísima para esta vida y la futura"; "La escuela, al intentar formar al hombre debe procurar formarlo totalmente para hacerle igualmente apto para los negocios de esta vida que para la eternidad." (Comenio, 1996:65).

3 "... nos ocuparemos de su formación en piedad y demás virtudes, no menos que en las artes liberales"; "Se confesarán todos por lo menos una vez al mes..."; "Absténganse por completo de juramentos, ultrajes, injurias, difamaciones, mentiras... En suma, de todo lo que vaya en contra de las buenas costumbres." (Ratio Studiorum, 1986:118-119).

${ }_{4} " . .$. pueden emplearse otros medios mejor que los golpes. Unas veces con ásperas palabras y püblicas amonestaciones, otras, alabando y ensalzando a otros"; y luego agrega que la disciplina debe aplicarse de tal modo que "... el mismo que la sufre se dé cuenta de que se le aplica en su provecho y proviene del amor paternal." (Comenio, 1996:66).

${ }^{5}$ El maestro debe estar "... sentado en lo alto de su cátedra-donde pueda ser visto y oído por todos- extienda como el sol sus rayos sobre todos" y agrega "... no hablarán sino cuando sean escuchados; nada enseñaran sin ser atendidos." (Comenio, 1996:67)

"...estimulen a los discípulos con pequeños galardones privados..., o algún distintivo de victoria, cuando uno ha vencido a su contrario...."; "... habrá que mostrar a cada profesor el registro de las notas de sus discípulos, antes de que se lea en público." (Ratio Studiorum, 1986:71-68)

7 "Al principio de cada año escolar señale él mismo, o por medio de los profesores, a cada discípulo, su banco y compañeros de asiento..." (Ratio Studiorum, 1986:69).

${ }^{8} \mathrm{~J}$. Trilla al referirse a las propuestas didácticas de los siglos XVII, XVIII, XIX y XX, nos dice: "...quizáa tengan poco en común, salvo que todos ellos son formas de asumir la realidad colectiva que constituye la escuela: todos son educatorios comunes de la infancia y la juventud". (Trilla, 1995:22).

${ }_{9}^{9}$ Con esto nos distanciamos de una serie heterogénea y contradictoria de teorías lingüísticas postmodernas que niegan la realidad por fuera del lenguaje: R. Barthes, J Derrida, D. La Capra, entre otros
} 
papado y que apoyaba el sentido de individualidad, libertad y progreso de los protestantes, los príncipes que buscaban autonomía ${ }^{10}$. Ante la "amenaza protestante", la orden de los jesuitas surgió como un instrumento fuerte de conservación y defensa de la ortodoxia católica que respondía directamente al Papa: para ello los jesuitas diseñaron y perfeccionaron, a lo largo de décadas, una propuesta didáctica que atendía al control individual y la vigilancia estricta del cumplimiento de normas, conductas, y principios ${ }^{11}$ en la educación del clero, la nobleza y un sector de la burguesía que, por intereses, apoyaba la causa católica. Ahora bien, la Reforma no logró imponer sus principios a los sectores más bajos de la población, antes bien, en este ámbito social prevalecieron las supersticiones, el misticismo y un conjunto de creencias mundanas ancestrales: a este sector (más propenso a aceptar una religiosidad que acepte las imágenes, los santos, los rituales) intentó llegar la contrarreforma, y los hermanos La Salle diseñaron con este fin una propuesta didáctica que incluía la ayuda económica para que esta "infancia" pueda asistir a la escuela y que estaba destinada a "moralizar" a la población menos educada.

Pasemos a analizar ahora las propuestas didácticas de algunos autores actuales más relevantes.

Zabala Vidiella (1999), insiste en sus análisis sobre la función social que cumple, o que debería cumplir, la Escuela, y en la necesidad de organizar secuencias didácticas, de contenidos, de recursos, de la evaluación, en definitiva, de la clase, el espacio y el tiempo. Ahora bien, las variables teóricas y metodológicas que maneja se encontrarían según el autor en los postulados del constructivismo y del enfoque globalizador, y su intención no sería imponer una forma de "cómo enseñar" (según el subtítulo) sino intentar "proponer algunos criterios que contribuyan a articular una práctica tan reflexiva y coherente como lo permitan las condiciones presentes en un momento determinado".

La preocupación por la función social de la Escuela y la enseñanza también la comparte Zabalza (1997), aunque este recalca la necesidad de evaluar las necesidades y analizar las situaciones concretas de cada contexto educativo, sin dejar de tratar el tema de los objetivos, los contenidos, las estrategias y la evaluación. En cambio, en la obra de Gimeno Sacristán (1989), que contiene artículos de varios autores, se analiza en profundidad la problemática de la transmisión cultural y del currículo no-escrito, se focaliza en la necesidad de la investigación didáctica y en una reconceptualización-reconstrucción de la teoría del currículo, sin dejar de lado los temas referidos a objetivos, contenidos, formación, evaluación.

Contreras Domingo (1994), invita a los docentes a tomar postura en toda elección didáctica y a prestar mayor atención a la comunicación, la psicología del aprendizaje y diversas cuestiones epistemológicas; además, cuando analiza el tema del currículo •su diseño, desarrollo y evaluación• insiste en la necesidad de la investigación, la reflexión y el cambio. Este autor recurre con bastante frecuencia a los trabajos de Carr y Kemmis (1988), fieles aplicadores del pensamiento de Habermas en la educación. Estos últimos se proponen más bien desarrollar una postura filosófica desde la cual se puedan desarrollar postulados "sobre" • aunque ellos prefieren decir "para"• la teoría, la investigación y la práctica educativa, e insisten en que cada docente debe construir su propia teoría de la enseñanza mediante una continua autorreflexión crítica.

\footnotetext{
${ }^{10}$ Esta relación entre el protestantismo y los principios del liberalismo y el capitalismo fue una de las tesis principales del sociólogo alemán Max Weber.

$"$ "... muéstreles las reglas de nuestros alumnos, para que se enteren de cuál debe ser su comportamiento." " Señale en cada clase..., un censor público, o si no agradare este nombre, un decurión máximo o pretor." (Ratio Studiorum, 1986:66-71).
} 
A continuación citamos algunas afirmaciones de cada uno de estos autores por ser sumamente relevantes para entender mejor las transformaciones que se han dado en el campo de la pedagogía y de la didáctica: $^{12}$

- Zabala Vidiella (1999): "...el libro parte de la idea según la cual los docentes... son profesionales que deben diagnosticar el contexto de trabajo, tomar decisiones, actuary evaluar la pertinencia de las actuaciones, a fin de reconducirlas en el sentido adecuado" (p.7).

- Carr-Kemmis (1988): "Este libro intenta proponer... una justificación filosófica de la postura según la cual los enseñantes tengan un papel especial como investigadores, y que la manera más plausible de construir la investigación educativa sea una forma de ciencia social crítica" (p.20).

- Camilloni (1996): "...reconocimos que cada una de nosotras tiene una particular óptica y entendimos que la didáctica hoy se genera con ese entrecruzamiento de miradas y dimensiones de análisis" (p.9).

- $\quad$ G. Sacristán (1989): "No podemos dar recetas porque creemos que no son posibles, aunque sí se dispone de experiencia acumulada y de análisis que llevan a recomendar unas orientaciones prácticas sobre otras" (p.14).

- Contreras Domingo (1994): "La didáctica es la disciplina que explica los procesos de enseñanza-aprendizaje para proponer su realización consciente con finalidades educativas" (p. 13).

Diagnóstico, propuesta, investigación, construcción, diversidad de posturas, experiencia, recomendación, orientación, crítica, conciencia... Resulta impensable imaginar a Comenio, o a los Jesuitas, hablando en estos términos. Por supuesto, los términos en sí mismo no son nada, sino en tanto logran transformarse en conceptos significativos que reflejan un determinado estado de la cuestión. En ese caso, podríamos concluir afirmando que en los libros actuales de didáctica se observan diversas transformaciones: 1. se han abandonado las explicaciones causales simplistas sobre la enseñanza; 2. ya no se busca regir la práctica docente mediante pasos mecánicos y formalizados; 3. se tiene una visión compleja sobre las relaciones entre los contenidos, los objetivos, las actividades de los alumnos, las tareas y la intervención pedagógica; 4. se busca la promoción de procesos de construcción social de significados por parte de los alumnos y; 5 . la evaluación es considerada como un proceso constante de autorreflexión y de regulación.

En sintesis: la diferencia fundamental, tal como lo señala Susana Barco (1989), entre las didácticas de los siglos XVII y XVIII y las del siglo XX reside en que las primeras son normativas, mientras que las segundas son solamente prescriptivas: lo normativo tiende a legislar, a imponer una finalidad sin consenso, mientras que lo prescriptito se basa en principios consuetudinarios, y funciona como guía y orientación flexible; no impone, recomienda; no exige, propone.

\footnotetext{
${ }^{12}$ En todas las citas las cursivas son propias.
} 


\section{El "aula" de los Hermanos La Salle: una aproximación genealógica}

Ya hemos hecho referencia al contexto histórico-social en el que se desarrolló la propuesta didáctica de los hermanos La Salle, pasemos ahora a analizar, especificamente, las características que tenían las "aulas" en las que se desarrollaba, o intentaba desarrollar, su forma de enseñanza.

En primer lugar, debemos recordar que La Salle fundó sus escuelas a partir de donaciones de los ricos o de ayuda de los municipios con el fin de crear y sostener un sistema educativo destinado a alentar a las familias más pobres a que mandasen a los niños a la escuela. Anteriormente, ya hemos dado las razones de porqué se preocuparon por este sector social que hasta entonces no había asimilado los principios de la reforma protestante.

Sus objetivos, preocupaciones y estrategias quedaron plasmados en su Manual para los maestros, que con el correr del tiempo, y tras la divulgación de esta forma de enseñanza, se convertirá prácticamente en la guía por excelencia de la Pedagogía Elemental. La misma trataba, en sus tres partes, las siguientes cuestiones: lo que debían hacer los alumnos durante todo el tiempo que estén dentro de la escuela; como se debía mantener el orden en las clases; y los criterios de inspección y formación de los maestros.

Una de sus innovaciones en el ámbito áulico fue realizar una sintesis metodológica que permitió combinar el método global de Comenio $^{13}$ con el método individual de los Jesuitas, pero teniendo características propias: las escuelas de los Hermanos La Salle estaban destinadas a los sectores sociales más pobres ${ }^{14}$ y por ello la educación tenía diferentes objetivos y contenidos. Dussel y Caruso $(2000)^{15}$ nos brindan una descripción •claro que con el fin de permitir entender mejor la genealogía del aula de los elementos más importantes que caracterizaban el aula de Comenio: uso de un método global, comunicación jerárquica, ritualizada, autoridad sin pura imposición, unificación de la autoridad en una persona $\bullet e l$ maestro ${ }^{16}$, uso de técnicas del yo basadas en la obediencia reflexiva, gradualidad, conducción grupal y obediencia colectiva ${ }^{17}$. Y también del aula de los jesuitas: método individualizante, relaciones entre enseñanza-gobierno y prédica, formación de cuerpos letrados, grupos de 200-300 alumnos, enseñanza de latín, griego, literatura y religión, empleo de la lección como interrogatorio, actividades continuas, contacto personal maestro-alumno, memorización-repetición, obediencia individual, sistema de notas, ubicación según méritos.

En las aulas de los Hermanos La Salle todo estaba estrictamente controlado, pues toda acción o asunto era atendido por el maestro: a esto se denominó la Pedagogía del Detalle. Dentro de este sistema de vigilancia y control, el silencio era una cuestión de primer orden: se consideraba que la comunicación por medio de señales y sonidos •es decir una comunicación ritualizada, no verbal• era fundamental dentro del aula para mantener la disciplina y el orden.

\footnotetext{
${ }^{13}$ "Si nunca se instruye uno sólo sino a todos al mismo tiempo y en una sola vez."; "Es evidente la utilidad que reporta el tratar todos en cada clase de una sola materia el mismo tiempo. .." (Comenio, 1996:70).

${ }^{14}$ Aunque la Ratio Studiorum también dice: "Pero no excluya a nadie por ser de condición humilde o pobre" (La Ratio Studiorum, 1986:66).

${ }^{15}$ Los autores defienden una postura foucaultiana de análisis basada en el estudio del aula según el método genealógico que implica una historia con toma de postura para rastrear los elementos matrices que se han ido construyendo históricamente como categorías y que configuran una determinada realidad.

${ }_{16}$ "... ha de ser fácil en extremo que un solo preceptor sea suficiente para un grupo muy numeroso de discípulos..." (Comenio, 1996:72).

${ }^{17}$ Narodowsky (1994:78), sostiene que los tres elementos que aseguraron el mecanismo general de la educación contemporánea ya se encontraban en la obra de Comenio: esto es, un dispositivo de alianza escuela-familia, un sistema de simultaneidad y un ente coordinador e integrador que es el Estado.
} 
Una innovación, muy llamativa, fue la maximización de la relación maestro-grupo de alumnos por medio de la lectura colectiva •pública y audible• e individual •cada alumno con su propio libro•. En este sistema de lectura con libros iguales se encuentran los gérmenes de los futuros manuales escolares.

Como sabemos, los Jesuitas introdujeron el sistema de "notas" como estimulante para la competencia y la emulación. Este sistema también fue utilizado por La Salle como una tecnología que sirviera para la ubicación de los alumnos según el mérito de cada uno •la meritocracia $\bullet$. Además, tomaron de los Jesuitas la utilización del castigo corporal, aunque lo que primaba era el castigo de las almas a través de la internalización de la normatividad, un ideal que ya estaba presente en Lutero.

Otra innovación fue el empleo de la lengua materna como primera lengua de enseñanza, en este caso el francés, reemplazando al latín, que ahora paso a ser la lengua utilizada solamente en la enseñanza superior.

El elemento característico de las aulas de La Salle era la distribución serial del espacio • diferente a Comenio, en cuya aula los alumnos formaban una masa bastante difusa $\bullet$ mediante la asignación de lugares individuales para cada alumno según su adelanto, valor, carácter, aplicación, limpieza, fortuna que permitía controlar, vigilar, clasificar, jerarquizar, distinguir, recompensar o sancionar a cada alumno según sus circunstancias particulares. Como lo señala Foucault (2002:151): "Al asignar lugares individuales, ha hecho posible el control de cada cual y el trabajo simultaneo de todos. Ha organizado una nueva economía del tiempo de aprendizaje. Ha hecho funcionar el espacio escolar como una maquina de aprender, pero también de vigilar, de jerarquizar, de recompensar."

Pese a las diferencias que había entre el aula ideada por Comenio, el de los Jesuitas o el de los Hermanos La Salle, el elemento común que atraviesa a uno u otro tipo ideal de aula es la disciplina. Un tipo especial de disciplina que se ejercía por medio de diversas tecnologías: 1. la distribución de los alumnos en el espacio, ya sea a través de rangos, grados, meritos o castigos; 2. el control de las actividades de los alumnos a través del control del empleo del tiempo •cantidad y calidad• la articulación de sus actos con los gestos y con los objetos que manipulan •elaboración temporal del acto• y con un empleo positivo del tiempo •utilización exhaustiva•; 3 . la vigilancia jerárquica, continua y funcional de los alumnos a través de la observación constante y el encauzamiento de la conducta; 4. las sanciones normalizadotas, a través de micropenalidades •sobre el tiempo, las actividades, las maneras de ser, la palabra, el cuerpo... • y el doble sistema de gratificación-sanción. En definitiva, una disciplina que "... atraviesa todos los puntos, y controla todos los instantes de las instituciones disciplinarias, compara, diferencia, jerarquiza, homogeneiza, excluye. En una palabra, normaliza." (Foucault, 2002:188).

\section{Figuras de la infancia: el "contenido" de la "forma"}

Todas las propuestas didácticas que hemos analizado anteriormente se apoyaron en una determinada concepción de la "infancia", para lo cual necesitan construir, por medio del discurso pedagógico, determinadas imágenes y representaciones sobre los distintos tipos de infancia, esto es, darle una "forma" y especificar todo lo que se les debía enseñar o, en otras palabras, llenarlos de un "contenido". Varela - Uría (1991), siguiendo una perspectiva foucaultiana, distinguen tres figuras de infancia a las cuales califican como "naturalezas de Oro, Plata, Hierro", y esto por dos razones principales: en primer lugar, 
porque al referirse a metales pretenden mostrar como la "infancia", o las distintas "infancias", son consideradas como materia prima que necesita ser formada y modelada para darle una utilidad que se considera necesaria $^{18}$; y en segundo lugar, porque cada una de éstas infancias recibirá una educación diferente de acuerdo al sector social que integran, según características económicas, sociales, políticas y culturales que se pretenden "naturalizar". Naturalizar la infancia, naturalizar la escuela, en definitiva, naturalizar el orden social reinante: "La escuela no existió siempre, de ahi la necesidad de determinar sus condiciones históricas de existencia en el interior de nuestra formación social".(p. 14).

Además, debemos tener siempre presente que la pedagogía no sólo construyó un determinado tipo de sujeto •la infancia• sino también toda una producción discursiva destinada a imponer una normatividad específica, un conjunto de saberes, para esta nueva categoría sociopolítica.

- El infante y el caballerito: como pertenecían a la Aristocracia Cortesana de donde provendrían los futuros gobernantes, serán objeto de una educación de buena calidad destinada al aprendizaje de buenas maneras de actuar y comportarse, letras y literatura, buenas costumbres. Serán educados por maestros y preceptores domésticos que los atenderán de manera particular según los principios humanistas vigentes. Tras esta educación preparatoria, terminarán yendo a la Universidad a estudiar las carreras consideradas más prestigiosas en aquel entonces: cánones y leyes.

- El colegial: se refiere a los miembros del Estado Medio y de la Aristocracia Provincial, que por lo general eran los que ocupaban las funciones públicas. Estos eran educados en colegios religiosos, especialmente en colegios jesuitas que utilizaban diferentes técnicas, exámenes, ejercicios, competencias, para ayudarlos a desarrollar las facultades más elevadas del hombre - razonar, pensar, comprender • necesarias para el buen desempeño de sus futuras funciones

- El pícaro: es el participante de los grupos heterogéneos integrados por niños de distintas edades y niveles de instrucción, destinados a ser futuros trabajadores manuales y empleados domésticos y laborales de los anteriores grupos sociales. La base de su aprendizaje estaba dada por las doctrinas cristianas, y la enseñanza que recibían estaba orientada al aprendizaje de oficios, de hábitos y de una ética del trabajo que exigía y necesitaba el nuevo orden socioeconómico para mantenerse estable.

\section{Reforma y Lectura en la modernidad: rupturas y continuidades}

Sabido es que la Historia de la educación en la Edad Moderna estuvo estrechamente relacionada con la reforma protestante. Tal como lo afirman Dussel y Caruso (2000), la historia de Europa occidental cobra sentido si la contextualizamos dentro del marco de los enfrentamientos de las dos confesiones (protestantes y católicos) que la dividían. Ahora bien, en la historiografía una línea de debate constante sobre la Reforma y las transformaciones que esta ocasionó o no, se ha centrado en la importancia del libro y la lectura en la difusión del protestantismo, contra la importancia del culto y la liturgia en el catolicismo. Es cierto

\footnotetext{
${ }^{18}$ Sabemos que la definición de un estatuto específico de la infancia fue una pieza clave en el surgimiento de la escuela, tal como lo ha analizado P. Aries, siendo retomados muchos de sus aportes por Mariano Narodowsky. Este último ha escrito: "...las investigaciones inauguradas por Aries demostrarán que la infancia es un producto histórico moderno y no un dato general y ahistórico que impregna toda la historia de la modernidad." (Narodowsky, 1994:28)
} 
que el libro fue mucho más central en la estrategia de la reforma y la contrarreforma católica de lo que muchos autores tradicionales habían admitido pero, por otro lado, otros historiadores han sobre-valorado la importancia de una relación mecánica entre Reforma e imprenta. Lo que sí queda de manifiesto es que la reforma y la cultura escrita, pretendiendo formar un espacio de reflexión teológica y cristiana, terminaron siendo centrales en la formación del espacio público moderno y del proceso de secularización.

El historiador Jean-Francois Gilmont (1998), tras analizar la relación entre las reformas protestantes y los tipos de lectura concluye afirmando que su análisis le ha conducido a dos exégesis contradictorias de la historia de la lectura, ya que aunque la Reforma lo cambió todo, resulta ser por otro lado que la Reforma no cambió nada...

Para entender el sentido de esta proposición, es necesario tener en cuenta algunos puntos esenciales de su análisis.

Por un lado, el autor afirma que la Reforma se dio paralelamente a una revolución en los medios de comunicación, por la invención de la imprenta, y que, gracias al servicio que la misma prestó a las ideas protestantes, el libro actuó como un agente eficaz de la Reforma, tanto para llegar a los analfabetos como a los sectores instruidos: "El libro sirvió de fuerte apoyo a la acción de los propagadores de la Reforma frente a sus auditorios, fueran éstos analfabetos o no." (p.359). Sin embargo, por otro lado, al autor sostiene que no hay que magnificar el impacto que la imprenta (y con ella el librol tuvo en una sociedad mayoritariamente analfabeta, y por ello insiste en no perder nunca la "omnipresencia de lo oral': "En la difusión de la Reforma, el recurso a lo escrito no excluyó nunca el uso de la palabrd" (p.349), y más adelante agrega que, "...el impacto de esos impresos en una sociedad en gran medida analfabeta no se comprende sin la mediación de la palabrd' (349). Este cambio en la relación con el texto se dio porque cuando la lectura se generalizó, junto con ella se generalizaron las distorsiones, las auto-interpretaciones y las herejías dogmáticas, por lo cual se debió recurrir al control de las creencias por medio de la predicación.

De ahí que llegue a la conclusión de que, durante la etapa de la reforma, lo que en realidad existió fue un "... entrecruzamiento de las prácticas de lectura." (p.347).

Dentro de este proceso, notamos que, en la historia de la lectura, la Reforma, por un lado lo cambió todo: facilitó la divulgación de autores antes condenados al silencio; contribuyó a la "fijación" estable de las lenguas nacionales al difundir las doctrinas en las lenguas vulgares; posibilitó la generalización de la lectura; dificultó el control estatal o eclesiástico sobre la circulación de las ideas, lo que originó la difusión de las ideas científicas y políticas que impulsaron los cambios de la sociedad; privilegió la educación escolar como un elemento esencial para la sociedad; socavó la concepción sacralizada sobre las Sagradas Escrituras, llevó a una familiarización con la Biblia. Pero por otro lado, la Reforma no cambió nada en el sentido de que no hubo una revolución en la relación con lo escrito, continuó la primacía de lo oral, la dependencia de la predicación, la vigilancia teológica, la lectura de la Biblia según comentarios y no se fomentó la lectura popular libre.

Por ello, los interrogantes que aun persisten son: ¿qué influencias ejercieron los libros protestantes sobre la forma de pensar de las personas? ¿Cómo influyeron en la alfabetización de los sectores rurales? ¿Qué papel cumplieron en el fomento de la cultura? Pese a las dudas que existen al respecto, lo cierto es que es necesario matizar los efectos de los "textos" según los "contextos" en los que circularon y fueron 
apropiados, es decir matizar el papel que cumplieron las religiones según las sociedades: "La lectura y las reformas protestantes constituyen sin duda un juego circular de influencias reciprocas entre sociedades y religiones." (Gilmont, 1998:365).

\section{Consideraciones finales}

La "infancia" fue una construcción de la modernidad. Las formas y contenidos diseñados e implementados por Comenio, los jesuitas, los hermanos La Salle y los maestros protestantes establecieron las bases del sistema educativo moderno y constituyen hasta hoy día los fundamentos de la educación contemporánea.

La comprensión de las características y modalidades de la enseñanza instituida por la modernidad es esencial para entender el presente de la educación y proponer alternativas viables para nuestra realidad.

Analizar genealógicamente la matriz histórica de las actuales propuestas didáctico-pedagógicas, no es sólo una práctica cientifica, es una lupa indispensable para mirar las sendas antiguas y observando los caminos recorridos por la educación poder ver con claridad dónde se encuentra y hacia dónde se dirige.

\section{Bibliografía}

AGUIRRE, María Esther (1993). "De una propuesta curricular llamada Didáctica Magna". En: ALBA, Alicia de; coord. El currículo universitario. De cara al nuevo milenio. 2 ed. México, Plaza y Valdés.

BARCO DE SUEGHI, Susana (1989). "Estado actual de la pedagogía y la didáctica". En: Revista Argentina de Educación. Año 7, № 12, mayo-junio de 1989, pp. 7-24.

BERNSTEIN, Basil (1988). Clase, código y control. Hacia una teoría de las transmisiones educativas. Madrid, Akal.

BOWEN, James (1992). Historia de la Educación Occidental. El Occidente moderno. Tomo III, España, Herder.

CARR, W. y S. KEMMIS (1988). Teoría Crítica de la enseñanza. La investigación-acción en la formación del profesorado. Barcelona, Martínez Roca.

CAMILLONI, Alicia y otros (1996). Corrientes didácticas contemporáneas. Buenos Aires, Paidos.

CONTRERAS DOMINGO, José (1994). Enseñanza, currículum y profesorado. Introducción crítica a la Didāctica. $2^{a}$ ed., Madrid, Akal.

DUSSEL, Inés y CARUSO, Marcelo (2000). La invención del aula: Una genealogía de las formas de enseñar. Buenos Aires, Santillana.

FOUCAULT, Michel (2002). Vigilar y Castigar: nacimiento de la prisión. Buenos Aires, Siglo XXI.

GILMONT, Jean Francois (1998). "Reformas protestantes y lectura". En CAVALLO Guglielmo y Roger CHARTIER. Historia de la lectura en el mundo occidental. María Barberán (trad.), Madrid, Taurus, pp. 329-365.

GIMENO SACRISTAN, J. y PEREZ GOMEZ, A. (1989). La enseñanza: su teoría y su práctica. $3^{a}$ ed., Madrid, Akal.

NARODOWSKY, Mariano (1994). Infancia y Poder: la conformación de la pedagogía moderna. Buenos Aires, Aique.

KEMMIS, Stephen (1993). El currículum, más allá de la teoría de la reproducción. 2 ed. Madrid, Morata.

TRILLA, Jaume (1995). Ensayos sobre la escuela; El espacio social y material de la escuela. Barcelona, Laertes Ediciones.

VARELA-URIA (1991). Arqueología de la escuela. Madrid, Ed. La Piqueta, p.14

ZABALA VIDIELLA, Antoni (1999). La práctica educativa: cómo enseñar. Barcelona, Graó.

ZABALZA, M.A. (1997). Diseño y Desarrollo curricular. Madrid, Narcea. 
Fuentes:

LABRADOR, C. et al. (1986). La "Ratio studiorum" de los jesuitas. Traducción al castellano, introducción histórica y temática. Madrid, UPCM.

COMENIO, J.A. Didáctica Magna. En: Páginas Escogidas. Prólogo de Jean Piaget. Buenos Aires, A-Z Editora, 1996. 